\title{
Bromodomain Inhibitors in Degenerative Eye Disease; An Alternative to VEGF Inhibitors in Macular Degeneration?
}

\author{
Joseph W Eichenbaum* \\ Adjunct Associate Professor of Ophthalmology and Pharmacology, Icahn School of Medicine, USA
}

*Corresponding author: Joseph W Eichenbaum, Adjunct Associate Professor of Ophthalmology and Pharmacology, Icahn School of Medicine, Mount Sinai, USA.

Received Date: December 24, 2019

Published Date: January 10, 2020

\begin{abstract}
For over a decade VEGF (Vascular Endothelial Growth Factor) inhibitors have been the definitive treatment of choroidal neovascularization associated with adult onset macular degeneration. While the induction of "wet macular degeneration" treatment requires 2-3 intravitreal injections, over 2-3 months, the maintenance phase for sustained good visual acuity may be 6 injections or more per year, protracted over 6-8 years. Unfortunately, this treatment, even if the extended number and time of intravitreal injections could be packaged in a sustained delivery device, would still not represent a cure. Alternatively, if the treatment could be targeted to genetic, oxidative stress, inflammatory and immune modification from Bromodomain inhibitors (BRD I), (which would work through these transcription factors from an early stage to correct these macular problems), then patients might be given a more direct and shorter intervention with perhaps oral maintenance as necessary. Similar consideration for BRD I may be developed for uveitis, corneal scarring and retinal ganglion cell protection.
\end{abstract}

Keywords: Macular degeneration; VEGF Inhibitors; Bromodomain inhibitors; Uveitis; Corneal scarring; RGC (Retinal Fanglion Cell) protection

\section{Introduction}

\section{Development of the optimal treatment}

VEGF inhibitors (Bevacizumab, Ranibizumab, and Alfibracept), with comparable efficacy, have become the gold standard of treatment of acute and recurrent choroidal neovascularization associated with adult onset macular degeneration (AMD), the leading cause of vision loss in the elderly [1-5]. The induction phase to reduce fluid in the macula requires $2-3$ injections. The maintenance of good visual acuity after two years is unfortunately based on monthly intravitreal injections [1-6].

\section{Evolution of the optimal treatment}

CATT [6] and IVAN [5] studies showed that "as necessary" injection rates of treatment up to two years did not result in as good visual acuity as fixed monthly injections. After two years the CATT study showed loss of the vision gains with only 4-5 injections per year [6]. Since the average AMD patient is 78 years old and expected to live about another 8 years, even though the "as necessary" VEGF injection rate may work in some patients, it is probably inadequate for the majority [1]. However, the continuation of monthly intravitreal injections over the duration may be difficult.

Thus, the treat and extend option has been used. This means that after follow up if there is evidence, usually on OCT (a noninvasive imaging of the retinal layers and their thickness) or OCTA (a non-invasive imaging of the retinal layers and their blood flow) of enhanced macular leakage, an additional intravitreal injection of VEGF inhibitor is given after the exam. That usually results in 6-8 injections per year to maintain good visual acuity, so far as we know, out to 3-4 years. And this has been able to maintain good visual acuity $[1,7]$.

\section{Discussion}

VEGF inhibitor problems with vision maintenance over time in the sizeable undertreated Groups: Real World Utilization of Anti-VEGF agents

However, from large data groups like the Medicare data and others, where the average was only 4-5 injections per year, 
maintenance of vision gains beyond two years is lacking [8-10]. Many of the patients in other studies even in the first year are only getting less than 4 injections per year [1]. The AURA study from Europe showed loss of vision with under treatment in just two years [11]. Poster Data from EU retina 2017 in Barcelona, Spain showed $75 \%$ of the patients were getting less than 6 injections per year even in the first year of management [1]. Most of the studies show a direct correlation between number of injections per year above 6 and maintenance of good visual acuity [1]. A study from Sweden, for example, with seven-year retrospective registry and large number of patients showed a significant drop in vision after two years with loss to follow up or lower number of injections per year [12].

Likewise, in diabetic macular edema and retinal vein occlusion where VEGF inhibitors are also used for their vision sparing effect, the burden of therapy is beyond three years [1,9]. Thus, despite longer acting or higher concentration VEGF inhibitors or depot or sustained release of the drug that are on the horizon, durability of treatment is a long-term issue and VEGF inhibition is not a cure, but rather a continued maintenance therapy.

\section{Viral gene carriers}

Based on the phase 1 trial with 12 patients (aged 8-44 years) with RPE65 associated Lebers Congenital Amaurosis given one subretinal injection of adeno-associated virus containing a gene encoding a protein for isomer hydrolase activity of the retinal pigment epithelium (RPE) showing vision improvement (especially in children)[13], perhaps much more widespread gene therapy research to target AMD in senior adults may be useful in the future. For example, genes that trigger production of specific VEGF inhibitors or alternatively limit the production of VEGF in early AMD settings may be useful.

\section{BRD I: Degenerative pathways: oxidative stress, hypoxia/ inflammation, immune reaction, mitochondrial/ lysosomal instability: wet, dry AMD}

Photoreceptor and RPE protection by inhibiting certain proteins that control histone acetylation, which genomically regulate degenerative pathways of oxidative stress, inflammatory/ immune dysfunction and mitochondrial/lysosomal instability in AMD, may represent an alternative, comprehensive approach to both "dry" (geographic atrophy) and "wet" (choroidal neovascularization) AMD. Drusen (oxidative stress degenerative lipoprotein deposits between the retinal basal lamina and Bruchs), lipfuscin (from inefficient protein clearance from impaired mitochondrial/lysosomal pathway), geographic atrophy (RPE drop out and hyperplasia after inflammatory and immune dysfunction) and choroidal neovascularization (from chronic hypoxia and inflammation) are core processes [14-17] that may come under the purview of the histone/genomic modification machinery cited above. Bromodomain proteins through histone acetylation, a routine operation of the chromatin scaffold, which orchestrates gene activation, may be inhibited to reduce inflammation and immune dysregulation as well as Nrf2 (nuclear factor erythroid 2/ antioxidant response element). In RPE cells, the NRF2/antioxidant element regulates oxidative stress by enabling nuclear antioxidant gene activity and antioxidant proteins. Mice models with NRF2 deficiency are more susceptible to oxidative stress damage, protein aggregations and poor regulation of autophagy genes. The reductions of autophagic clearance of damaged proteins as well as the larger number of dysfunctional mitochondria are significant contributors to AMD [15,17-19].

BRD Inhibitors as Gene and RGC Protectors, Antiinflammatory Agents, Anti-Fibroblast Agents? oral BRD Inhibitors

Using a mouse model with a mutation for Retinitis Pigmentosa, by inhibiting bromodomain (BRD) and extra terminal domain (BET) after intravitreal injection of JQ1 (a specific BRD inhibitor), photoreceptor degeneration was reduced and electro retinographic function improved. Retinal microglia activation, marked by IBA1, CD68, TSPO, and mRNA inflammatory cytokines, TNF $\alpha$, MCP-1, IL-1B, IL-6 and RANTES were all suppressed. This would suggest a sparing role against retinal degenerative mutant genes by BRD inhibition [20]. JQ1, one of the more well studied BRD I, has a diazepin like structure see (Figure 1) and because of its similarity to diazepam drugs, which enjoyed widespread use in the 1980s and 1990s, the JQ1 potent stereoisomer might be able to be compounded into oral preparations(Figure 1).

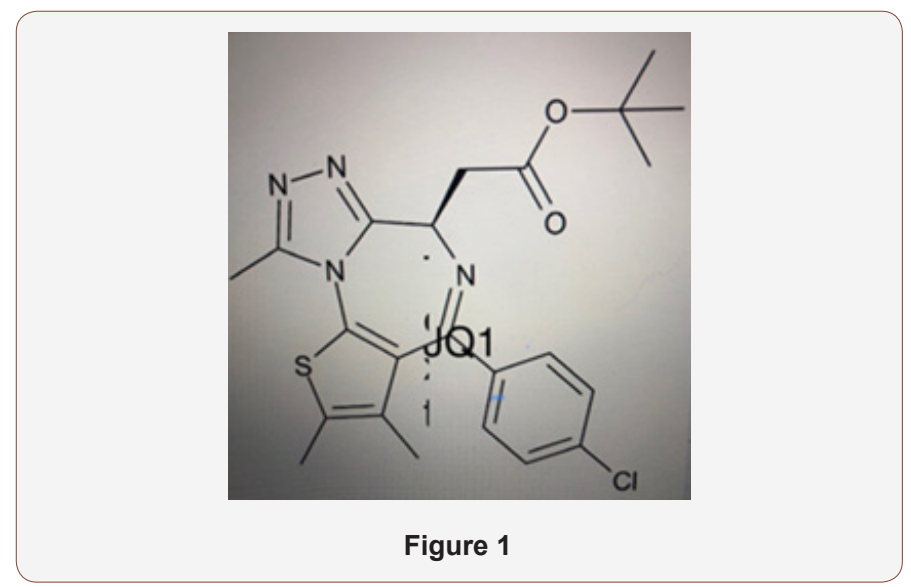

Using a mouse retinal ganglion cell (RGC) damage model induced by N-methyl-D-aspartic acid (NMDA) intravitreal injection with or without JQ1 in one eye, suppressed up regulation of inflammatory cytokines, TNF $\alpha$, IL-1B, MCP-1, RANTES in retinal homogenates by about $50 \%$ and maintained the number and gene expression of RGC at $\sim 2$ fold versus controls [21].

In another study of the potential effect of JQ1 on mechanical injury induced mouse corneal scarring and TGF $\alpha$ induced human corneal myofibroblast differentiation, mouse sub-conjunctively injected JQ1 suppressed corneal scarring without impairment of epithelial regenerative capacity and JQ1 or small interfering RNA inhibited the differentiation of human corneal myofibroblasts. The study concluded that JQ1 suppresses and reverses corneal scarring through BRD4 inhibition and Nrf2 dependent antioxidant induction [22]. Nrf2, a key transcription factor in cellular protection 
from reactive oxygen species facilitates the sustaining role of the mitochondria for energy generation as well as mitochondrial stability in maintaining the ubiquitination process of degenerative waste product removal in a timely and efficient fashion [15, 23,24].

Chromatin, the protein scaffold of the DNA that is affected by key controlling genes called transcription factors is alternately modified by histone acetylation versus de-acetylation, which regulate gene expression, In general, after acetylation of lysine residues on histones and key transcription factors, which might include bromodomain proteins, the chromatin structure is loosened and gene transcription/activation is carried out. After de-acetylation the chromatin structure is condensed, and certain key genes are repressed. Histone deacetylases HDACs are enzymes that remove acetyl groups. They are a large family of proteins, comprised of four classes of HDACs and seven sirtuin groups. Sirtuins are enhanced HDACs that can de-acetylate lysine residues in non-histone proteins within or outside the cell nucleus, such as in the mitochondria. While HDACs historically are linked to chromatin condensation and gene repression, HDACs may also act as gene promoters as well. For example, HDAC3 functions as a co-repressor when targeted by co-repressor molecules, but it is also necessary for transcriptional activation of retinoic acid response elements necessary for cell growth and differentiation [25].

The BET and BRD family are characterized as acetylation readers. By associating with hyper-acetylated chromatin regions these proteins promote transcription of target genes, such as those for immune or inflammatory, or mitochondrial function. Since the retina is one of the highest oxygen consuming tissues in the body the photoreceptors have the greatest density of mitochondria of all the CNS neurons [26]. Thus, with excess oxidative stress, mitochondrial energy production may be compromised as well as the ability to clear damaged wasted products [15,23,24].

\section{BRD inhibitors possible use in uveitis}

In a mouse model of experimental autoimmune uveitis in which CD4+Th1 and Th17 cells are immunopathogenic, mimicking noninfectious uveitis in humans, exposure to BET inhibitors, GSK151 and JQ1, downregulated Th17 associated genes IL-17A, IL-22 and retinoic acid related orphan receptor $\gamma \mathrm{t}$, illustrating therapeutic potential for uveitis and inflammatory and immune diseases [27].

\section{Mapping BRD inhibitor selectivity, concentration and immune, inflammatory, metabolic and long-term side effects}

Much work in the use of BRD inhibitors still needs to be done. For example, in the realm of cancer, each BET protein controls distinct transcriptional pathways that have functions beyond cancer cell proliferation, such as insulin production, cytokine gene transcription, T cell differentiation, adipogenesis and repression of latent HIV virus. Sound understanding of BRD inhibitor selectivity, concentration, and immune/inflammatory, metabolic, and degenerative risks need to be assessed in all clinical applications [28] (Table 1).
Table 1: BRD Inhibitory Activity in Degenerative Eye Disease Models.

\begin{tabular}{|c|c|c|c|}
\hline Animal & Delivery & $\begin{array}{l}\text { BRD Inhibitor } \\
\text { Site of Action }\end{array}$ & Authors \\
\hline Mouse & Intravitreal & $\begin{array}{c}\text { Retinitis } \\
\text { Pigmentosa } \\
\text { Genes, } \\
\text { photoreceptors, } \\
\text { ERG }\end{array}$ & $\begin{array}{c}\text { L Zhao, et al. } \\
\text { [20] }\end{array}$ \\
\hline Mouse & Inravitreal & $\begin{array}{c}\text { Retinal } \\
\text { Ganglion Cell } \\
\text { protection after } \\
\text { NMDA stress }\end{array}$ & J Li, et al. [21] \\
\hline Mouse & $\begin{array}{l}\text { Th17 enriched } \\
\text { cultures }\end{array}$ & $\begin{array}{c}\text { Reduced } \\
\text { inflammatory } \\
\text { cytokines and } \\
\text { uveitiogenic } \\
\text { activity }\end{array}$ & $\begin{array}{c}\mathrm{M} \\
\text { Eskandarpour } \\
\text { et al. [27] }\end{array}$ \\
\hline $\begin{array}{c}\text { Mouse/Human } \\
\text { Fibroblasts }\end{array}$ & $\begin{array}{c}\text { Mouse } \\
\text { intracorneal/ } \\
\text { Human } \\
\text { myofibroblasts }\end{array}$ & $\begin{array}{l}\text { Decreased } \\
\text { corneal scarring } \\
\text { and human } \\
\text { fibroblasts }\end{array}$ & M Qu, et al. [22] \\
\hline
\end{tabular}

\section{Conclusion}

From the above discussion one may infer that BRD inhibitors may have a pivotal role in attenuating the degenerative effects of chronic oxidative stress as in macular degeneration as well as the unbridled effects of inflammatory gene expression in the evolution of choroidal neovascularization. In addition, the BRD inhibitors may be useful in uveitis, retinal ganglion cell protection in glaucoma, and corneal scarring.

However, their selectivity, dosimetry, and potential side effects need to be delineated.

\section{Acknowledgement}

None.

\section{Conflicts of Interest}

Author has no conflicts of interest.

\section{References}

1. Regillo C, Talcott K (2018) Sustained anti-VEGF delivery or conventional injections. Gupta OP and Hsu J (eds), Wills Eye Knowledge Portal Chairs.

2. Rosenfeld PJ, Brown DM, Heier JS, Boyer DS, Kaiser PK, et al. (2006) Ranibizumab for neovascular age-related macular degeneration. N Engl J Med 355(14): 1419-1431.

3. Brown DM, Kaiser PK, Michels M, Sourbane G, Heier JS, et al. (2006) Ranibizumab versus Vertiporfin for age related macular degeneration. N Engl J Med 355(14): 1432-1444.

4. Heier JS, Brown DM, Chong V, Korobenik JF, Kaiser PK, et al. (2012) Intravitreal alfibercept (VEGF trap-eye) in wet age-related macular degeneration. Ophthalmology 119(12): 2537-2548.

5. Chakravarthy U, Harding SP, Rogers CA, Downes SM, Lotery AJ, et al. (2013) Alternative treatments to inhibit VEGF in age-related choroidal neovascularization: 2-year findings of the IVAN randomized controlled trial. Lancet 382(9900): 1258-1267.

6. Martin DF, Maguire MG, Fine SL, Ying GS, Jaffee GJ, et al. (2012) Ranibizumab and bevacizumab for treatment of neovascular age-related macular degeneration: two-year results. Ophthalmology 119(7): 13881398.

7. DeCroos FC, Reed D, Adam MK, Satz D, Gupta OP, et al. (2017) Treat and extend therapy using Alfibercept for neovascular age-related macular degeneration: A prospective trial. Am J Ophthalmol 180: 142-150. 
8. Lad EM, Hammill BG, Qualls LG, Wang F, Cousins SW, et al. (2014) Anti-VEGF treatment patterns for neovascular age related macular degeneration among medicare beneficiaries. Am J Ophthalmol, 158(3): 537-543.

9. Kiss S, Liu Y, Brown J, Holekamp NM, Almony A, et al. (2014) Clinical monitoring of patients with age-related macular degeneration treated with intravitreal Bevacizumab or Ranibizumab. Ophthalmic Surgery Lasers and Imaging Retina 45(4): 285-291.

10. Holekamp NM, Liu Y, Yeh WS, Chia Y, Kiss S, et al. (2014) Clinical utilization of anti-VEGF agents and disease monitoring in neovascular age-related macular degeneration. Am J Ophthalmol 157(4): 825-833.

11. Hykin P, Chakravarthy U, Lotery A, McKibben M, Napier J, et al. (2016) A retrospective study of the real-life utilization and effectiveness of ranibizumab therapy for neovascular age-related macular degeneration in the UK. Clin Ophthalmol 10: 87-96.

12. Westborg I, Grandstam E, Rosso A, Albrecht S, Karlsson N, et al. (2017) Treatment for neovascular age-related macular degeneration in Sweden: outcomes at seven years in the Swedish Macular Register. Acta Ophthalmol 95(8): 787-795.

13. Maguire AM, High KA, Auricchio A, Wright JF, Pierce EA, et al. (2009) Age Dependent effects of RPE65 gene therapy for Leber's congenital amaurosis: a phase 1 dose escalation trial. Lancet 374(9701): 15971605

14. KaarnirantaK, Salminen A, Haapasalo A, Soininen H, Hiltunen M (2011) Age related macular degeneration: Alzheimer's disease of the eye? J Alzheimer's Dis 24(4): 615-631.

15. Felszeghy S, Viiri J, Paterno JJ, Hyttinen JMT, Koskela A, et al. (2019) Loss of NRF-2 and PGC- $\alpha$ genes leads to retinal pigment epithelium damage resembling dry age-related macular degeneration. Redox Biol 20: 1-12.

16. Ambati J, Fowler BJ (2012) Mechanisms of age-related macular degeneration. Neuron 75(1): 26-39.

17. Eichenbaum JW (2019) Key transcription factors linking macular degeneration and Alzheimers disease. WJOphthal and Vision Res 1(4): 3-11
18. Feher J, Kovacs M, Artico C, Cavalotti A, Papale C, et al. (2006) Mitochondrial alterations of retinal pigment epithelium in age related macular degeneration. Neuro biol Aging 27(7): 983-993.

19. Ferring ton DA, Kapphahn RJ, Leary MM, Atlano SR, Terluk MR, et al. (2016) Increased retinal mtDNA damage in the $\mathrm{CFH}$ variant associated with age related macular degeneration. Exp Eye Res 145: 297-277.

20. Zhao L, Li J, Fu Y, Zhang M, Wang B, et al. (2017) Photoreceptor protection via blockage of BET epigenetic readers in a murine model of inherited retinal degeneration. J Neuroinflammation 14(1): 14.

21. Li J, Zhao L, Urabe G, Fu Y, Guo LW (2017) Epigenetic intervention with a BET inhibitor ameliorates acute retinal ganglion cell death in mice. Mol Vis 23: 149-159.

22. Qu M, Zhang X, Hu X, Dong M, Pan X, et al. (2018) BRD4 inhibitor JQ1 inhibits and reverses mechanical injury-induced corneal scarring. Cell Death Discovery 4: 64 .

23. Pajares M, Jimenez MN, Garcia YA, Escoll M, DeCeballos MI, et al. (2016) Transcription Factor NFE2L2/Nrf2 is a regulator of macro autophagy genes. Autophagy 12(10): 1902-1916.

24. Wei Y, Gong j, Yashoda T, Eberhart C G, Xu Z, et al. (2011) NRF2 has a protective role against neuronal and capillary degeneration in retinal ischemia reperfusion injury. Free Radical Biol Med 51(11): 216-224.

25. Manzotti, G, Ciarrocchi A, Sancisi V (2019) Inhibition of BET proteins and histone deacetylases (HDACs): crossing roads in cancer therapy. Cancers (Basel) pp. 11(3).

26. Moos WH, Faller DV, Glavas IP, Harpp DN, Irwin MH, et al. (2017) Epigenetic treatment of neurodegenerative ophthalmic disorders: An Eye to the future. Bio Res Open Access 6(1): 169-181.

27. Eskandarpour M, Alexander R, Adamson P, Calder VL (2017) Pharmacological inhibition of bromodomain proteins suppresses retinal inflammatory disease and downregulates retinal Th17 cells. J Immunol 198(3): 1093-1103

28. Andrieu G, Belkina AC, Denis GV (2017) Clinical trials for BET inhibitors run ahead of the science. Drug Discov Today Technol 19: 45-50. 